Modern Asian Studies 55, 3 (2021) pp. 938-972. (C) The Author(s), 2020. Published by

Cambridge University Press. This is an Open Access article, distributed under the terms of the Creative Commons Attribution licence (http://creativecommons.org/licenses/by/4.o/), which permits unrestricted re-use, distribution, and reproduction in any medium, provided the original work is properly cited.

doi:Io.ror7/Soo26749X200oorgo First published online i9 June 2020

\title{
'Our Grandmother Used to Sing Whilst Weeding': Oral histories, millet food culture, and farming rituals among women smallholders in Ramanagara district, Karnataka*
}

\author{
SANDIP HAZAREESINGH
}

History Department, The Open University

Email: sandip.hazareesingh@open.ac.uk

\begin{abstract}
The cultural and historical dimensions of rural lives matter. However, development practitioners and writings tend to play down these aspects. This article demonstrates the significance of oral history in revealing the meanings of women smallholders' milletbased foodways in southern India. It argues that women farmers' cultural practices around food constitute fundamental 'capabilities' nurtured over a long historical duration, and are essential to any meaningful articulation of 'development'. Drawing on age-old spiritual beliefs and practices involving non-human entities, the women demonstrate fine-tuned skills in nurturing seeds and growing crops, in preparing and cooking food, and in discerning food tastes, particularly in relation to the local staple ragi, or finger millet. They also express their creativity in the joys of performing songs and farming rituals linked to the agricultural cycle. In this way, cultural capabilities
\end{abstract}

* Acknowledgements: I am grateful to the management and members of the Green Foundation, particularly the chief executive officer Sandip Pattanayak, for facilitating this research. Deepest gratitude to all the women farmers and their families in the villages of Kanakapura in Ramanagara district who received us with amazing hospitality and enthusiastically shared their memories and experiences. Thanks also to the anonymous reviewers of MAS for their helpful suggestions. Finally, special thanks to Tsveti Bandakova and Udaya Aradhya, my fellow researchers on the Oral History project, for their dedicated work in carrying out the interviews, and to Sara Penrhyn Jones for producing the wonderful videos. Here's to the convivial times shared.

Disclosure statement: No potential conflict of interest was reported by the author.

Funding: The research leading to this article was supported by the AHRC under Grant AH/ROO4072/I, Changing Farming Lives in South India, Past and Present. 
express significant dimensions of women's agency exercised in the intimately related spheres of food and farming. Oral history thus emerges as a research method capable of generating insights into concrete manifestations of culture over a significant historical duration, one that is particularly conducive to reclaiming the voices and life experiences of subaltern groups such as women smallholders who are either not heard or are marginalized in written contemporary and historical documentary records.

\section{Introduction}

The Betsimimisaraka, we don't have books. We don't write history. We don't have photos. We remember through our land. I will be remembered by what I leave on the land. After I am gone, people will perhaps one day sit in this tree, and talk about me. (Osterhoudt 20I7, 54)

Culture is the source of our collective memories and our social imagination, and is both the depository of historical experiences and the main resource for conceiving and mapping humane and viable futures for our planet ... If ultimately development means the enhancement and protection of life, then it is through culture that this is achieved. (Clammer 20I5, 5)

In recent years we have seen the emergence of studies arguing for the relevance of historical and cultural perspectives in international development. In the development sub-field of agrarian studies, scholars have acknowledged the 'special light of history' for revealing alternative ways of knowing and acting in the rural world, seen as characteristic of an emerging 'critical agrarian studies' research paradigm (Edelman and Wolford 2017). There have been detailed accounts of the historical evolution of indigenous crops and farming practices in the climatevulnerable regions of Malawi and China (Bezner Kerr 20I4; Liu et al. 2016). In a similar vein, contemporary debates about food sovereignty, on the one hand, and cash crops, on the other, have been examined as part of longer historical processes in the context of Venezuela in the case of the former (Schiavoni 20I7), and of Malaysia and Indonesia in the case of latter (Bissonnette and De Koninck 20I7). Interestingly, Braudel's key historical concept of the longue durée has been used to explore the changing nature of rural life and agricultural crises in Kenya and Zambia over the past hundred years (Moore 20I8). In such instances, the view through a historical lens has provided a wider and richer perspective to the primarily 'presentist' mode of discussing and understanding these subjects, revealing 'the continuities that exist between the present and the past which shape the character, flow and possibilities of people's lives without necessarily being apparent to them' (Moore 2018, I502). 
While this emerging trend back towards history has tended to come from within the field of development studies, the most convincing advocates of cultural approaches have generally been located in other disciplines. The sociologist John Clammer has recently argued that culture, and the expression and development of its 'concrete manifestations' in what people actually do, constitute in a very real sense 'development' as they create spaces of meaning, enjoyment, and creativity that reveal a social group's most cherished values (Clammer 2018). He further points out that, with very few exceptions, discussion of these concrete manifestations tends not to feature in the existing development literature, even in writings avowedly concerned with development and culture (Clammer 2015, 6). In contrast, anthropology, particularly its major sub-field of cultural anthropology, has traditionally focused on understanding cultures on their own terms. Indeed, the recent 'ontological turn' in cultural anthropology towards highlighting the spiritual and cosmological interactions between people and nonhuman entities (Whitaker 20I9) offers new possibilities for recognizing and valuing alternative non-secular worlds and cultures. ${ }^{1}$ Sarah Osterhoudt's recent study of a vanilla-cultivating farming village in Madagascar shows how crop-cultivating agroforestry landscapes are also imbued with cultural meanings and historical memories based on a spiritual, non-secular ontology. Here ancestors, trees, and plants have agency and influence, directly informing the resilient everyday practices of contemporary farmers. Significantly, her account is partly based on a specific local epistemology known as tantara or oral history, gathered from specialist practitioners among the local villagers (Osterhoudt 2017). In a similarly anthropological vein, Anand Pandian has shown how the Kallars of southern India continue to draw on ethical agrarian traditions inherited from their colonial past as a cultivating caste, as they search for virtuous and harmonious ways of living amid the contradictions of their contemporary post-colonial experience. In this study, earth acts as 'conscience and witness to justice', so cultivating the land is also about cultivating the self, a moral and cultural endeavour that provides its practitioners with directions for a good life (Pandian 2009).

This article has affinities with both these studies and makes use of oral history methodology to explore the world of women small farmers and

\footnotetext{
${ }^{1}$ My thanks to Penelope Anthias for alerting me to the existence of a literature on political ontology.
} 
their foodways, that is, the local cultures of food and associated farming practices and rituals historically based on ragi, or finger millet, in the Kanakapura taluka (sub-district) of Ramanagara district, Karnataka in South India. The focus on small farmers or smallholders is based on an increasing recognition of their pivotal role in sustainable agriculture and food production in India and the global South more generally. Smallholders who, typically, cultivate on less than 2 hectares of land comprise 80 per cent of India's farmers and produce 40 per cent of the country's food grains, despite owning less than one-third of all farming land (Pande and Savenije 20I6). Globally, small farmers provide at least one-third of the world's food supply, ${ }^{2}$ with influential policy-making bodies such as the Food and Agriculture Organisation of the United Nations (FAO) now perceiving these producers as crucial actors in the sustainable environmental management of land and its biodiversity, the mitigation of the impact of climate change, as well as in the preservation of cultural heritage (Maass Wolfenson 2013). Specifically highlighting farming women's experiences arises from the widely acknowledged and well-documented inequalities and discrimination faced by women working in agriculture. Although women make up around 65 per cent of farmers in India, less than i3 per cent of them own land owing to the patrilineal system of land inheritance coupled with the customary practice of women moving to their husbands' household and village upon marriage (Pionetti 2005, 49). As a result, they struggle to access credit and other economic resources. Moreover, the Indian government uses land ownership as the main criteria for being recognized as a 'farmer', so consequently rural women working on the land are mostly defined as 'cultivators' with inferior legal status (Oxfam India 2013, 2017).

The primary aim of this article, then, is to examine, through the rich possibilities of oral history, women smallholders' millet-based foodways or food culture which, in recent times, has been subjected to the threat of increasing rice consumption. Foodways refer to the study of the meanings of food production and consumption, including the historically derived knowledges, traditions, beliefs, rituals, and activities

\footnotetext{
${ }^{2}$ Much of the literature on the subject suggests a higher figure - typically as much as 70 per cent (ETC Group 2017), though this has been challenged recently on methodological grounds. A recent study puts the figure at $3 \mathrm{O}^{-} 34$ per cent while confirming some of the crucial strengths of smallholding farming: wider crop and micronutrient variety and greater resilience to climatic impact on food systems than large 'industrial' farms (Ricciardi et al. 2018).
} 
that shape social groups' understanding of their food-related practices (Kaplan 2012, 6). In a word, foodways are about how food intersects with culture and history. The women smallholders of Kanakapura belong to regional farming communities in southern India with a shared history of ragi-centred foodways. They express the meanings of these shared foodways through songs, performances, offerings, and rituals linked to producing, preparing, preserving, eating, and sharing food. In so doing, they reveal an ontological 'way of being' centred on a spiritual world where non-human entities such as deities, earth, seeds, animals, birds, and insects are closely related to humans and affect food and farming outcomes. The women render these foodways sustainable by applying knowledge practices pertaining to the local agrarian environment, seed selection and preservation, and the multiple use and nutritional value of crops - epistemologies that have been identified as the particular realms of women farming expertise in both India and the global South (Sachs et al. 1997; Pionetti 2005).

Foodways are a particularly amenable entry point for oral history research, with several studies indicating food's resonance with memories, in terms of its sensorial ability to trigger vivid memories of home, family, and associated activities (Kong and Sinha 2015, I2). As a research method, oral history can offer insights into food cultures over a significant historical duration and reveal alternative ontologies of food and farming to the secular assumptions characteristic of development theorists and practitioners (Wilson 2017). Memory and the process of remembering are at the heart of oral history, and this study draws primarily on the women farmers' life histories or autobiographical memory, which is 'continually conditioned by culture in time and space' (Wang et al. 2017, 200; Abrams 2016, 86). Moreover, this method is particularly conducive to reclaiming the voices and life experiences of subaltern groups such as women smallholders who are either not heard or are marginalized in written historical and contemporary documentary records. In addition to providing insights into the different worlds inhabited by these women, oral history also gives meaning to the concept of 'plural pasts' by showing how these groups 'have different histories and different understandings of what is going on' (Zeitlyn 2015, 387) from the predominantly male subjects of both historical and development narratives pertaining to rural society. Indeed, over-reliance on official colonial historical records and the consequent neglect of oral traditions have been identified as the main causes of the failure of the Subaltern school of Indian historians to represent the experiences of ordinary, mainly illiterate, rural women during the colonial period. The virtual 
erasure of women from these records translates into an unsurmountable obstacle to subaltern historians' aim and ability to articulate the full range of peasant modes of resistance to, and perhaps the more typical quiet subversions of, hegemonic colonial arrangements (Raheja and Gold I994, I4-I6). In contrast, the recording and analysis of oral histories, based on a collaborative engagement between interviewer and participant, potentially enables the retrieval of women's experiences, with all the accompanying rich emotions that are themselves a meaningful contribution to the research process (Baillie-Smith and Jenkins 2012). They bring to the fore the hidden and neglected histories of rural women, potentially enabling the disruption of accepted historical 'regimes of truth' based on written archives.

Finally, this article also aims to strengthen an emerging advocacy on behalf of the interconnected realms of the cultural and the historical as housing indispensable creativities hitherto not - or not sufficiently-accorded significance in agrarian and development studies. It argues that women farmers' foodways-related cultural and epistemological practices constitute 'capabilities' that help them to maintain, adopt, or recover sustainable ways of life which include confronting economic and climatic challenges. These capabilities encompass collective, non-secular knowledges and creativities thereby widening and complicating Amartya Sen's original concept, defined as what individuals 'are able to do and to be' (Sen I999; Nussbaum 2003). These practices also, to some extent, support them in confronting economic and climatic challenges. The focus throughout is on ontological 'ways of life' rather than on 'livelihoods' - the more familiar social science term - as this concept gives more space and visibility to the cultural ontologies and epistemologies that are as central to farmers' life experience as their material livelihoods. They encompass beliefs and desires, relationships with nature and the divine, as well as knowledges and performances, including gender-specific attributes.

Ramanagara is one of the newest districts in India, carved out of the Bangalore Rural district of Karnataka in August 2007 (see Figures I and 2). Of the total population, 59 per cent are engaged in agriculture, either as farmers, 'cultivators', or agricultural labourers. Smallholdings under three hectares of land constitute over go per cent of total holdings, with women making up the majority of cultivators and agricultural labourers. Ramanagara is very much ragi country, historically the staple food of southern Karnataka. This millet still predominates among cereal crops grown, ahead of paddy and maize, and smallholders cultivate it mostly under rain-fed conditions within a diverse cropping system. Crops rely primarily on the southwest monsoon rainfall (June-September) which, in a 


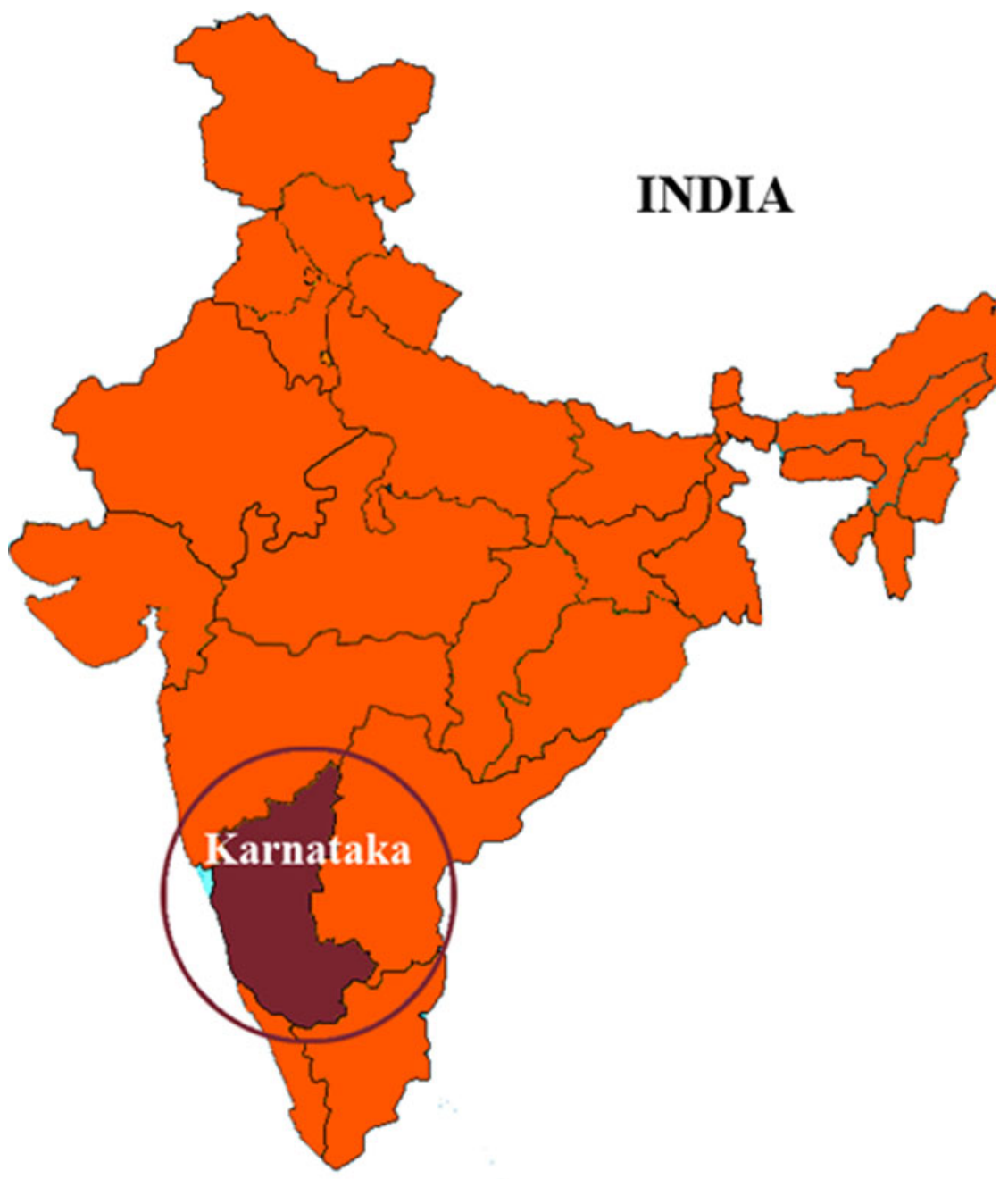

Figure I. Map of India showing the location of Karnataka. Source: Tsveti Bandakova, Oral History project.

dry agro-climatic region, is described as 'highly variable'. The only important commercial crops raised are mulberry, which provides a steady cash income, and sugarcane. In addition, oilseed crops, such as groundnut and sesame, and a wide variety of vegetables, pulses, and fruits, including beans, pigeon pea, aubergine, tomato, beans, mango, papaya, bananas, and coconut, are extensively cultivated (Government of India-hereafter GoI-20I4, $2,4^{-6)}$. 


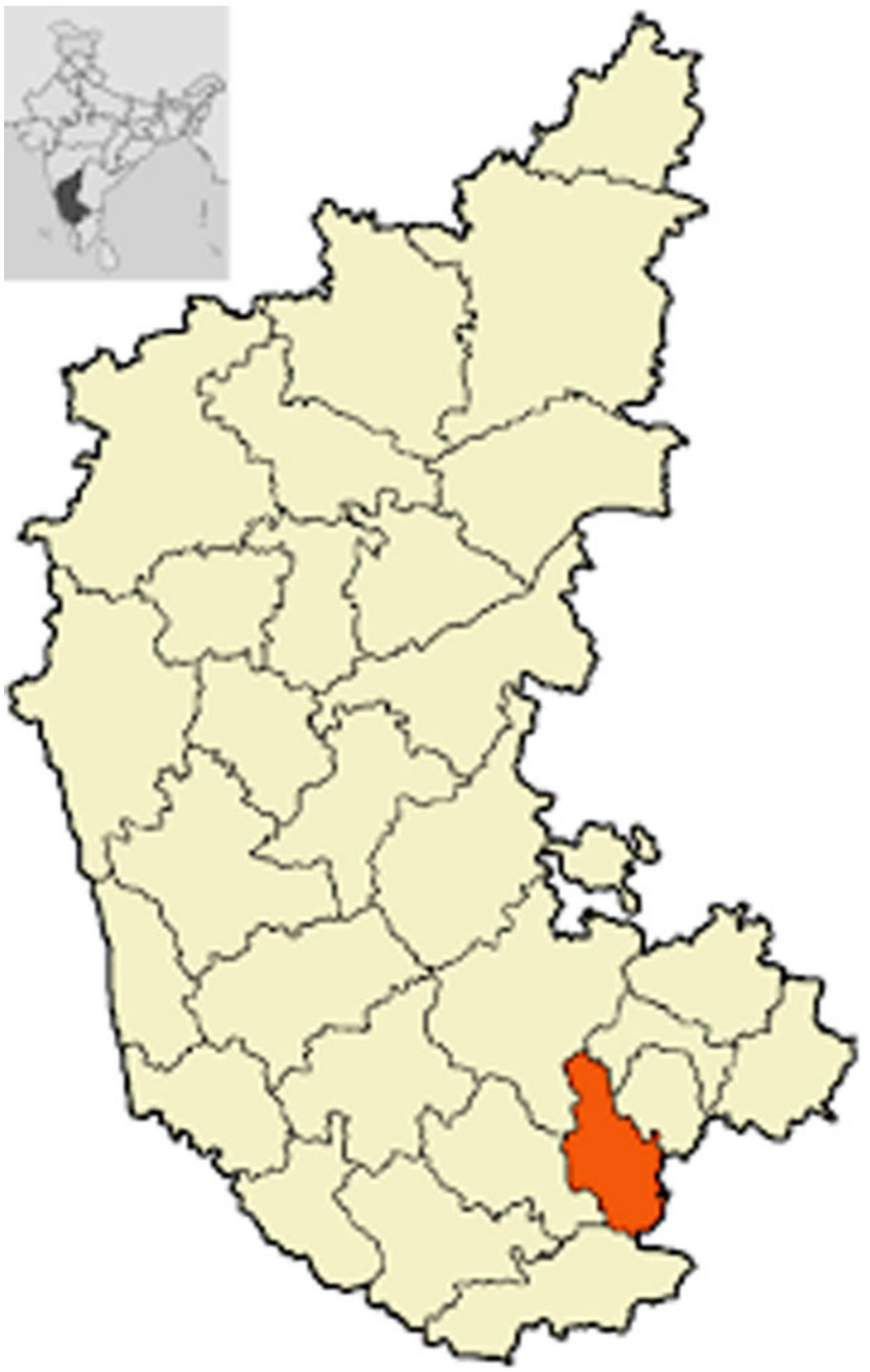

Figure 2. Map of Karnataka showing the location of Ramanagara district. Source: Tsveti Bandakova, Oral History project. 
Audio and filmed oral history interviews with i7 women farmers were mostly held in several villages of Kanakapura taluka (sub-district) between March and June 2018. The women were selected from a list provided by the NGO Green Foundation, our local partner in the research project, based on an expressed interest in telling their life stories. This was confirmed through an initial telephone conversation with the project translator who had grown up in the area and still had family there. There followed a short introductory visit to establish the aims of the oral history project and to confirm understandings and expectations. ${ }^{3}$ Main interviews were recorded digitally and lasted around an hour-and-a-half, usually followed up by one or two subsidiary sessions. Some of the participants were also filmed and short videos produced as a result. Although these interviews were semi-structured and tended to begin with questions that were primarily of interest to us as researchers, participants were encouraged to shape the narrative as much as they wished by talking about activities, subjects, and life episodes that they themselves regarded as significant and meaningful. As a result, this article focuses on the women's narratives of the things that they feel strongly about and are able to do and enjoy, rather than on the more familiar concern with the exclusions and disadvantages they face. As we shall see, this did not preclude them from talking about the challenges they have experienced, particularly the impact of changes in weather. Consistent with other research findings, we discovered that the women farmers were particularly passionate about foods and diets, and the beliefs, rituals, and knowledges associated with household foodways, much more so than about the economic specificities of crops and livelihoods. This was the case even among the minority of women who affirmed that they managed and controlled the household finances.

\section{Historical patterns of millet and rice consumption in South India}

Archaeological evidence suggests that ragi, or finger millet (Eleusine coracana), is likely to have travelled from East Africa to the Western Ghats region of India in the second millennium of the Neolithic period

\footnotetext{
${ }^{3}$ The broad aim of the oral history project was to document women farmers' memories about changes in local farming practices and in environmental conditions that they had experienced in their lifetimes.
} 
(around 2500 BCE). The appearance of this millet coincided with the first fixed human settlements and the emergence of farming in South India. 'Right from the beginnings of agriculture,' observes archaeologist Kathleen Morrison (2016, 362), 'southern Indian farmers were actively experimenting with plants and animals and were in contact with similarly innovative farmers elsewhere. This era may be seen as establishing the basic South Indian repertoire of rainfed millets and pulses, sown in synchrony with the southwest monsoon.' Morrison goes on to describe the subsequent development, from the later Iron Age, of differentiated 'wet' and 'dry' landscapes in southern India, as local chiefs built a series of tanks that enabled the cultivation of rice and a variety of other irrigated crops and dairy products derived from cattle grazing. By the fourteenth century, rice had become the foundation of elite cuisines that transformed regional landscapes and sustained the growth of temples, towns, and cities, enabling the emergence of the kingdom of Vijayanagara (1340-1672).

In contrast, cultivated on dry lands, millets and legumes defined the foodways of the poor majority, sustaining the vast world of peasant labour. Morrison cites the observations of Scottish botanist Francis Buchanan, who, reporting to the East India Company in I8oo on the potential wealth of the plant world of the newly conquered kingdom of Mysore, found that the ragi crop was 'by far the most important of any raised on dry field, and supplies all the lower ranks of society with their common food', and was perceived as 'the most wholesome and invigorating food for labouring people'. He also noted that his 'Bengal and Madras servants', who were 'accustomed to live on rice', viewed ragi 'as execrable food and would experience great inconvenience were they compelled to live upon it' (Morrison 20i6, 359).

The differentiated consumption of ragi and rice by specific classes of people in Karnataka continues to be recorded in the subsequent historical literature of the region. Reporting on agricultural trends in the then princely state of Mysore in I908, a century after Buchanan's travels, the Imperial Gazetteer of India observed that, 'ragi is the staple food of all the labouring classes, and if this crop fails there is widespread distress. Rice, which is the main irrigated crop, is not much eaten except by Brahmans, but always commands a ready sale for export' (Frowde 1908, 226). Very little seems to have changed by the late i940s when the anthropologist M. N. Srinivas conducted his study of the village of Rampura, in Ramanagara's western neighbouring district of Mandya. 'Rice,' he remarked, 'was a commercial crop for the majority of villagers. Ragi was their staple diet, and only a minority of rich 
landowners and Brahmins, ate rice regularly.' He further observed that 'the eating of rice was prestigious, and there was a reluctance to admit to eating ragi. Only the Brahmins ate rice to the exclusion of other grains, and rice-eating by the other castes was part of the general phenomenon of emulating the Brahmins' (Srinivas 2012, 137). Even as late as the I98os, the Gazetteer of India (the post-colonial successor to the Imperial Gazetteer), surveying the newly established Bangalore Rural district, was still able to confirm the dominance of ragi which remained 'the staple food of the people in the rural areas', with rice only eaten 'on festive days' and by 'a small section of the community' (Government of Karnataka - hereafter GoK-ig89, i77).

However, such official documents tell us little about the broader meanings of ragi foodways involving local farming communities' own experiences and perceptions. If everyday or habitual experiences are those that are more likely to be remembered in detail (Abrams 2016, 87), then the centrality of ragi in the daily lives of local farmers explains their ability to recall experiences stretching quite far back in time. During one interview, a group of elderly farmers in Belalam village on the Ramanagara/Tamil Nadu border remembered how villagers had organized the underground storing of ragi grains during the war years of the I940s to conceal the foodstuff from revenue officials. 'At that time, the British had passed a rule limiting how much of the crops the farmer could retain, the rest would be requisitioned and taken away by the revenue people,' they recalled. 'We were just adolescents back then, but we would help dig up the ground in such a way that it would not be apparent to outsiders that there was anything stored underground. The hole was 7 feet in depth, large enough to store about $5^{\circ}$ bags of ragi. We would spread the husks on the underground floor and then pour the grains on top. We would cover these with firewood planks and put some soil on top which would cover the entire edifice' (Interview with Shankarappa and family, 2I April 2018). In this way, oral history enables the discovery of new evidence that provides a deeper insight into the significance of ragi in local farmers' ways of life, while also suggesting the mostly untapped richness of hidden local histories of rural India.

\section{Women's stories of food and changing diets in Ramanagara district}

Significantly, all the women smallholders interviewed had something to say about the currently topical issue of millet versus rice consumption in 
Karnataka. Their evidence suggests that the sharp socio-historical distinction between labouring millet-eaters and elite rice-eaters has all but broken down in rural south Karnataka. Over the past 30 years in particular, rice appears to have made substantial inroads among traditionally millet-eating smallholders. Women recalled the pervasiveness of ragi in local diets during their childhoods, mainly in the rg6os and I970s, and earlier in some cases. 'As children, we were given ragi mudde (finger millet soft balls) in the mornings and evenings, and rotis made out of ragi, eaten with curd, in-between; we never had rice, and even chapati is a very recent food. But now, no one eats ragi, rice has taken over,' says Devaramma from Virayanadoddi village (Interview with Devaramma, I2 March 2018). As we probe her further and speak to more women, a more nuanced reality emerges: it becomes evident that ragi and rice coexist in virtually all households, with the main divide being essentially generational, though there also persists a cultural perception of ragi and millets as superior to rice in taste and nutritional qualities, and as the essential staple for a healthy diet. Ragi, and the ragi mudde dish in particular, continues to be eaten, though mainly by the older generation of villagers over the age of 6o; the younger generation of women farmers, and their menfolk, prefer cooking and eating rice. 'I myself enjoy the taste of ragi, but the daughters-in-law prefer rice which is quicker to make; preparing ragi mudde is physically demanding, it takes time and effort to achieve the required consistency,' explains Devaramma's neighbour Lakshmi Bai (Interview with Lakshmi Bai, 6 March 2018). 'These days men turn down mudde and ask instead for rice,' adds Ramakka from Billedalle village (Interview with Ramakka, 4 April 2018).

How do the women villagers themselves explain this shift in staple food consumption patterns? On one level, they agreed with Srinivas: having rice is definitely a status symbol, a display of affluence, Devaramma affirms. 'It means not to be associated with the poor man's food anymore.' She describes one of the ways in which the cultural taste for rice was popularized in her village, recounting a story from her childhood about a rich local landowner who was attending the village panchayat (council) and had fixed a grain of rice on his moustache, pointing to it, and telling people just how tasty rice was. Given the prestige commanded locally by powerful landowners back then, such demonstrations would have been quite persuasive. But she identifies the Public Distribution System (PDS) as the decisive influence, as it effectively brought rice into the homes of the majority of people in her village. 
Set up (or rather reformed and expanded) in the I970s by central government in the wake of the Green Revolution, the PDS aimed at ensuring food security at the household level throughout India. With a primary focus on access to staple grain, it sought to make rice available at highly subsidized prices in all rural areas through a chain of local fair price shops (FPS). In the southern states, this rice was not the locally known irrigated dryland paddy that had been cultivated for centuries and only consumed by the higher castes, but the hybrid Green Revolution varieties introduced all over India in the late I96os. However, the post-colonial state's approach to tackling hunger and banishing the spectre of famine experienced by the rural poor during colonial rule was based on ensuring calorie sufficiency rather than a balanced, nutritious diet (Pingali et al. 2017; Landy 2017). 'It became cheaper to buy rice than to grow ragi,' Devaramma observes. Coming from outside the region, moreover, this rice was perceived as new and exotic which, she suggests, added to its desirability. As a result, in her own family, they moved to cooking more rice than ragi dishes, and ragi was gradually reduced to being eaten at just one meal a day. The emergence of the hegemony of rice in rural smallholders' foodways, at least at the level of consumption, seems to have been determined by a range of converging trajectories: symbolic aspirations for status upliftfor cultural 'modernity' - created a receptive mood for the Indian state's rice promotion campaigns based on field demonstrations and a series of brochures and films produced by the Ministry of Information and Broadcasting. But this model of food security also represented a broader process of ideological persuasion as India's rural poverty became a priority for intervention by the United States in the context of the Cold War. In essence, American aid and agricultural experts remade Indian agriculture in the ig6os on the basis of hybrid crops, chemical fertilizers, intensified irrigation, and credit (Siegel 2018, I97, 208).

Nonetheless, we did get a sense that the story of ragi is perhaps not quite done yet: some of the women voiced a belief that millet foods are currently undergoing a resurgence. 'We eat ragi mudde for breakfast and dinner, with different pulses and vegetables because we know it's good for us,' Ramakka declares. 'If we feel hungry in-between, we cook some rice.' She adds that although her children have moved to Bangalore, they too continue to eat mudde. 'They take the ragi flour back with them whenever they come home to the village,' she tells us. Other households, like Kalamma's in Bannali village, also consume ragi twice a day as they believe that it has superior nutritional value compared 
with rice (Interview with Kalamma, 22 March 2018). There is unanimity among the women about the unique nutritional qualities of ragi. 'Rice is easily digested and passes through the body quickly, whereas ragi has more iron content, is digested very slowly, stays longer in the body, and therefore provides more stamina and strength,' Devaramma explains. 'In the villages, people have always known this and are now coming back to ragi,' she continues, observing that even in the cities people were becoming more health conscious and making ragi an important part of their diets. Although hers is a family that had reduced ragi eating to one meal a day, she is now planning to increase their millet consumption because of its nutritional benefits. Kamakshama, from Gollaradoddi village, tells us that while she used to feed her children mashed boiled rice when they were toddlers, she has noticed that her granddaughter gives her little children ragi in liquid form, which provides better nourishment: it is boiled with milk or water to make a paste and mixed with legumes and pulses such as moong dal (green gram) (Interview with Kamakshama, 21 March 2018).

\section{Tasty millets}

In Karnataka, moreover, the political emphasis once placed on rice consumption in the villages has been superseded by a current public campaign dedicated to the revival of millets, which are now described as 'nutri-cereals that are good to eat and grow and are kind to the planet' (GoK 2018). Spearheaded by a range of influential local actors, including farmer activists and organizations, and NGOs promoting sustainable agriculture, the agriculture department of the Government of Karnataka, the reputable University of Agricultural Sciences, the Indian Institute of Millets Research, as well as nutritionists and wholesale food suppliers, a broad social movement has emerged over the past decade-and-a-half aimed at making millets 'the food of the future' in Karnataka, 'the millet capital of India' (GoK 2018). Similar efforts are also ongoing in other parts of India and across the world (Chera 2017). Particularly emphasized are the nutritional and environmentally friendly advantages of millets in relation to rice, which include richness in protein, fibres, and micronutrients such as iron, zinc, and calcium in which rural women and children, in particular, have been found to be deficient. As $\mathrm{C}_{4}$ crops, moreover, they have a higher carbon intake and use water more efficiently, requiring just one-fifth of 
the amount needed to grow rice, and are also able to withstand higher land temperatures (Siddhartha, 2012). Hence, in a radical reversal of their long-standing identity as 'coarse grains' and as the food of the poor, millets are increasingly referred to as siridhanya or rich grains.

GoK initiatives include: paying more to millet-cultivating farmers by procuring ragi in south Karnataka at 20-25 per cent above the minimum support price (MSP) for agricultural produce, subsidized access to this millet for the first time through the PDS system and its fair price shops in the villages, and organizing millet festivals and trade fairs in Bengaluru (Raju et al. 20I9, I; GoK 2018). NGOs have focused on training farmers on various aspects of organic millet cultivation, raising awareness of its nutritional, environmental, and 'climate smart' benefits, and setting up the provision of resources such as seed banks and millet-processing facilities. ${ }^{4}$ GoK policies aim to address the production aspects of finger millet, with a view to securing higher levels of remuneration and profitability for farmers by increasing cultivation at the expense of competing crops such as maize. However, farmers have complained of long delays in receiving payment as well as a lack of storage facilities, which still only exist for rice and wheat. There remains, moreover, a long-standing cultural orientation towards growing ragi primarily for family consumption and food security rather than for the market (Raju et al. 2019, 3-6).

It is significant that many of the elderly women in the villages of Kanakapura remain passionate about the tastiness of millet foods, and we were often invited to share in a home-cooked meal of ragi mudde. Taste, and the cultural practice of tasting, express a sensual appreciation of food quality by these women who see themselves as the custodians of local cuisines and dishes. Taste may also be seen as an enabling and persuasive dimension of nutrition, and it is interesting that many of the women farmers found it difficult to dissociate these two aspects of millet foods. From a foodways perspective, taste has been identified as a form of 'sensory labour', an active knowledge practice that draws on family histories of discernment and remains crucial to sustaining vulnerable farming lives (Kantor 2019; Spackman and Lahne 2019). Now in her late eighties, Gundamma from Bellalam village has

\footnotetext{
${ }^{4}$ See the information provided by the following NGOs about their millet revival initiatives and activities: GREEN Foundation, www.greenfoundation.in; Amrita Bhoomi, https://amritabhoomi.org; Sahaja Samrudha, www.sahajasamrudha.org; Deccan Development Society, www.ddsindia.com; and, beyond southern India, the North East Slow Food and Agrobiodiversity Society (NESFAS), www.nesfas.in.
} 
particularly strong views about the preparation and taste of ragi and still vividly remembers how they used to prepare this millet when she was a young woman. 'Back then us women would sit and grind ragi until the roosters sang in the morning, we used to grind a lot of it, about $20-30$ kilos,' she recalls. Her face lights up as she adds 'we used the grinding stone and I have of course kept mine'. She deeply regrets that the grinding stone has nowadays given way to the flour mill where the ragi grains are processed into flour. 'When you use electrical appliances, it spoils the taste,' she declares, 'because it already comes out half-cooked.' 'When we were cooking stone-ground ragi, it used to be aromatic, but with mill-ground flour, the ragi mudde doesn't have the right smell and texture, and it's also less good for our bodies. Even now, I tell my daughters-in-law, use the stone to grind, see how tasty it will be, see how strong I am from eating stone-ground ragi' (Interview with Gundamma and Muniyamma, 28 April 2018).

Gundamma's narrative represents a particularly vivid instance of autobiographical remembering, sharpened here by the presence of the material artefact of the grinding stone. Making this meaningful item of farming equipment the centrepiece of her recollections vividly brings home how practices of ragi food preparation have changed in local villages over the past 30 years. Her feelings about the decline in the taste and nutritional components of contemporary ragi mudde is shared by other elderly women farmers. 'The taste is definitely better using the old method,' Shivratnamma from Bevinamaradadoddi village observes, adding that she too wants to obtain a grinding stone to process her ragi grains because 'we can't really trust the power-supply, it's so unreliable in this village' (Interview with Shivratnamma, 25 April 2018). Other women suggest additional reasons for the loss of taste, such as the superseding of previously grown local varieties of ragi by 'higher yielding' hybrid varieties introduced in the rg9os, coupled with the use of chemical fertilizers which largely replaced the natural, cow dung-based manures they recall using previously.

These farmers are clearly passionate about the ragi mudde dish, about how it should taste, and more broadly about the importance of good, healthy food for their families and communities. Remembering how such ragi-based dishes used to be prepared, cooked, and eaten in the past by the whole family often triggered memories of other locally cultivated pre-Green Revolution foods that were perceived as tasty and healthy, particularly the smaller millets and dairy products. This process has been described as 'edible memory' and provides a fascinating glimpse into how memory and materiality interact (Jordan 2015). 
Women described how they prepared delicious, fragrant millet 'rice' dishes from arka (kodo millet), saame (little millet), and navne (foxtail millet), eaten with sambhar (vegetable stew) made from a variety of local beans, with avarekai (hyacinth beans) standing out particularly on account of its deep, rich scent as well as its nutrients. This combination of millets and stews was perceived as particularly wholesome and tasty by women in the villages. Ramakka recalled the exquisite aroma of her favourite sweet dish, a foxtail millet kheer or payasam (pudding): 'We used to make it using the first milk of cows, which was boiled and then we added foxtail millet rice to make it thicker along with ground coconut, jaggery (unrefined cane sugar), and cardamom mixed in for flavour. Back then this dish used to be very tasty, but less so nowadays because foxtail millet is hardly grown so we have to use ordinary rice.' She also believes that there has been a decline both in the quality and quantity of milk. She explains that farmers no longer keep cattle in as large numbers as they used to 5o years ago, so there is less milk available and much of this tends to be sold to milk cooperatives to make a little extra money for the household, rather than kept for home consumption. Additionally, much of the fodder fed to cows and cattle is now purchased from government stores - it contains chemicals and tends to be of poor quality, so the milk the cows produce does not have the same taste or nutrients as before.

In essence, the women's narratives are not about food primarily as 'subsistence' but as the epitome of enjoyable experience, with pleasure taken in discerning, preparing, cooking, and eating in a convivial environment defined by family and community belonging. Their stories testify to the importance of the cultural dimension of food as well as the significance of historical perspectives in revealing how particular aspects of foodways can persist while others evolve and change over time. The strong feelings evoked about the taste of millet foods, past and present, speak perhaps to the enduring significance of these dishes as a marker of cultural identity among smallholders in this region. While the combination of farm work and household cooking responsibilities may be perceived as an onerous double-duty still shouldered by rural women, the women themselves have a somewhat different perspective. They see the delivery of tasty and wholesome meals as the rewarding end-product of their daily activities, as caring for loved ones, and protecting the household from the various diseases that continue to afflict life in the villages. This is an arena where farming women exercise significant agency, largely based on their sensory labour expertise which is deployed to provide or revive dishes that sustain both 
well-being and social relations within the family and community. Philosopher Martha Nussbaum has suggested that such productive use of the senses should be recognized as one of the central human capabilities conducive to living a dignified life and to promoting social and gender justice (Nussbaum 2003, 40-4I).

\section{Women sing and perform: folk-songs, field rituals, and food offerings}

Gundamma does more than just tell us about how ragi was prepared in the past. She also conveys a sense of the cultural performance involved in preparing finger millet using the grinding stone. As she and her sister-in-law Muniyamma demonstrate the whirling motion of the stone as it crushes the seeds, they begin to sing, the notes rising and falling with the rhythm of the whirling stone (see Figure 3):

In times of drought the lake is filled

The embankment has a fathom of water flowing, brother.

For over a thousand years, women in southern India have been singing songs while engaged in the various aspects of agricultural labour and food preparation. As a result, there emerged specific genres of farming folk songs associated with particular foodways activities, including ragi-grinding songs (Ramaswamy I993; Srinivas 2012). But labouring women could also flexibly choose from a wider oral cultural repertoire of popular folk songs, 'transferred' from other farming or village-related contexts. This song is an extract from a traditional ballad about an imminent threat of flood and the need to appease the water goddess Gangamma who continues to be worshipped by villagers in this region. Although in its original context, this genre of songs expressed popular environmental anxiety at the prospect of flooding (Shah 2012), transferred and adapted to the world of ragi-grinding, singing this ballad fulfils completely different functions. What is important here is not the 'meaning' of the song, but the emotional power generated by the singing voices, which dramatizes Gundamma's narrative about the grinding stone.

The performance suggests how, historically, singing has acted as an uplifting emotional resource for women engaged in the arduous labour of seed grinding, while also reinforcing bonds of conviviality and community. Even though the songs specifically associated with ragi-grinding seem to be fading from memory following the phasing out 


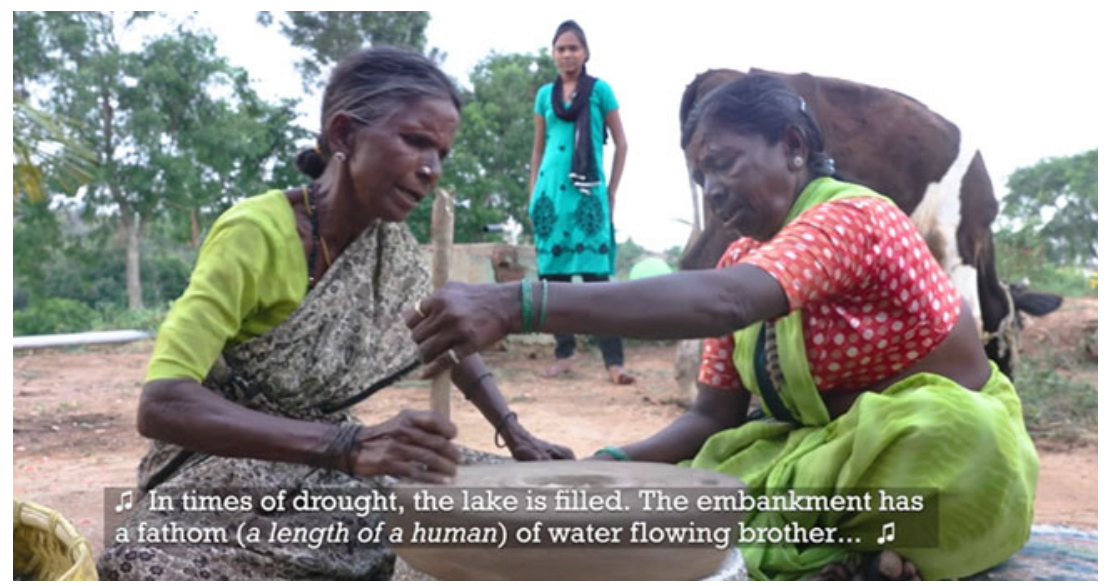

Figure 3. 'The grinding stone'. Source: Sara Penrhyn Jones, Oral History project; https:// vimeo.com/297060181.

of the grinding stone about 25 years ago, it is clear that folk songs have remained a significant aspect of the contemporary culture of these women farmers: during interviews, most of the women would sing quite spontaneously, often joined by the children in the household, as they recounted episodes of their life histories.

'Our grandmother used to sing whilst weeding the crops just before and after sowing,' recalls Shivamma, as we join her and her companions on the family farm in Allanatha village, where they are weeding mulberry bushes, which is mainly women's work. They are singing one of their usual weeding songs, and Shivamma explains (see Figure 4):

When I got married and started working on the farm, I started singing too, to keep the tradition alive. We feel like singing when working together ... singing and working are inseparable. If we sing in praise of God, then God may show mercy on us for our hard work because we are working in the hot sun. God will listen to our call.

The songs sung by the women mostly evoke spiritual beliefs involving goddesses (particularly) and gods, suggesting how intimately farming ways of life remain connected to wider systems of folk religious faith that nourish and sustain them. Beyond the secular, a crucial aspect of foodways activities involves reaching out to the divine and the spiritual, since good crops and food provision are ultimately believed to be the consequences of divine blessing (Pandian 2009, I67-I69). Farmers believe that soils and cultivated land represent one element 


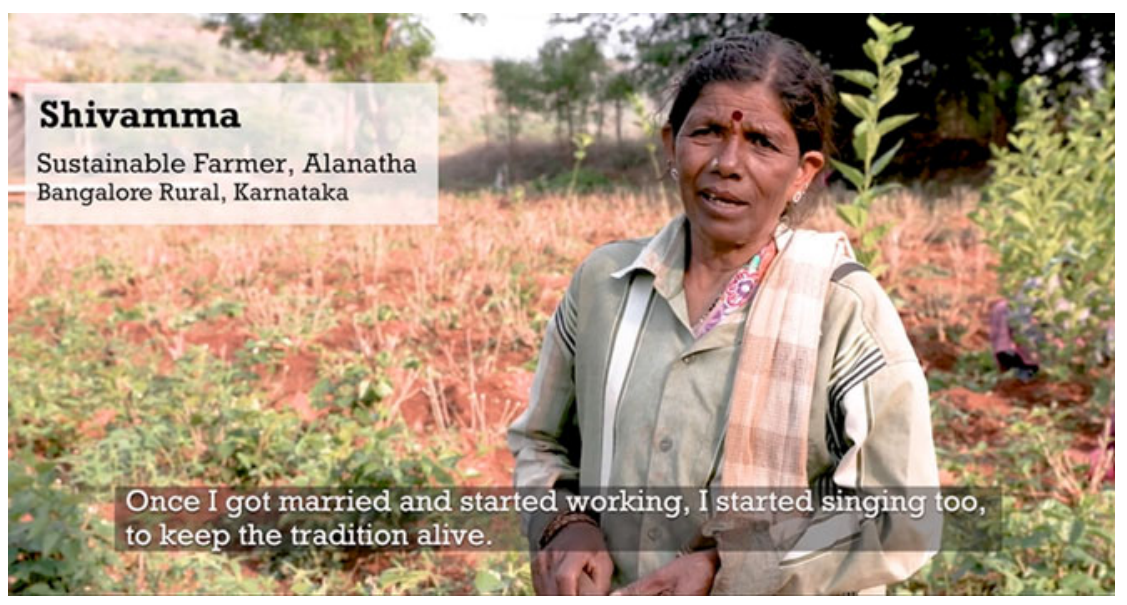

Figure 4. 'Our grandmother used to sing whilst weeding.' Source: Sara Penrhyn Jones, Oral History project; https://vimeo.com/289843096.

of the regenerative capacity of the earth, so the earth is also worshipped as a giving, bountiful goddess. 'We call her bhoomi tayi (Mother Earth),' Shivamma tells us. This worship is expressed in numerous songs, rituals, and ceremonies, performed in villages to mark different phases of the agricultural season. One particularly important ceremony is the koorge pooja (blessing of agricultural equipment and farm animals), which occurs at the start of the farming season, after ploughing and before the sowing of seeds, performed in the hope of securing a plentiful harvest. 'We've been doing this pooja (prayer) since time immemorial, long before I was born,' Kalamma explains. 'We wish to honour and care for Mother Earth so that she blesses our farm implements and animals, so we prepare a mixture of rice, sesame, and jaggery from a fresh harvest of sugar cane, which we offer to our Mother; and we also make an offering of coconut, beetle nut, and fruit to our oxen.' 'Then three women perform the sowing initiation,' adds Lakshmi Bai, 'one picks up some ragi seeds, puts them in her saree, and starts the sowing; the other two follow and do the same with togari bele (pigeon pea) seeds.' In this way, seeds, cattle, and farming implements are not seen merely as economic factors of production but as integral to a farming culture that encompasses feelings and reverence. Such a culture of worship expresses a way of being that is connected to a supernatural world in which goddesses and spirits have the power to influence farmers' everyday lives. This world is not seen as a 
separate, alternative sphere to the secular realm of farming activities, but rather as a connected one that provides a guiding light to these endeavours, ensuring that they are carried out in harmony with nature and the cosmos. Here it illuminates the millet/pulse choice and sequencing, underlining their enduring value as the prime seedlings of local food security and agro-ecological resilience. For centuries, ragi and pigeon pea have remained the dominant crops used in inter-cropping in Lakshmi Bai's village, with the nitrogen-fixing properties of the latter also enhancing soil fertility and increasing the nutrients available to other food crops.

In Karnataka, as elsewhere in India, all the main annual festivals combine religious rituals, a focus on food for both divine and human consumption, and connections to the agricultural season. The main festival of Ugadi, which celebrates the advent of the regional new year in March/April, also heralds the start of the harvest season. 'We celebrate Ugadi on the first day after the new moon as we believe this to be the most auspicious day for our future hopes,' says Devaramma, 'so we clean the house thoroughly and decorate the entrance with a garland of fresh mango and neem leaves.' Mango and neem trees possess sacred, auspicious status, the former endowing love and fertility, the latter warding off disease and evil spirits. The family prepare special luxurious food combining sweet and sour tastes, which symbolizes the changeable fortunes of life; the dishes include idli (savoury lentil and rice cake), vegetable curry, chutney, mango pickle, and the payasam dessert made out of boiled rice and coconut. The meal is first offered to deities as prasad before being eaten by the family. Prasad literally means 'auspicious gift' and denotes an edible, vegetarian food that is first offered to a goddess or god as an act of ritual generosity and then distributed to followers in the deity's name. Each person receiving prasad is thus divinely blessed and will hope, as a result, to enjoy both spiritual and material well-being. During festivals and religious ceremonies, women's control over food preparation endows them with a crucial mediating role in rituals supplicating deities. Moreover, in the life of the village, the gift-like properties of regular food sharing carries (much more than commodified food selling) a 'fundamental persuasiveness' (Adapon 2008, 42) which endows women with a capability to promote and strengthen ties of social reciprocity and solidarity.

Kalamma tells us about two other ceremonies that are performed on her farm around harvest time to thank Mother Earth for her bounty. The first, which is known as kachaki, occurs about a week before the 
crops are harvested: first, a hen is sacrificed in the field, and then a prasad, made from the crushed stems of ragi plants mixed with rice, is offered to Mother Earth. The second, rashi pooja, is a thanksgiving for the harvest held after the ragi crops are harvested and thrashed on the threshing ground to obtain the produce. The pooja is held on the threshing ground itself which is turned into a sacred space, revealing once again the continuum between the spiritual and secular worlds in the eyes of the farmers. Coconut (another sacred and health-bestowing food), mango leaves, and flowers are then offered to Mother Earth, to ensure that the land remains fertile for the following season. 'We also have a village festival where we offer pooja (prayer) ceremonies to the rain god Maleraya,' adds Shankarappa from Belalam village. 'The Maleraya Habba (Festival of the Rain God) has been celebrated for hundreds of years in every village in this region just before the expected arrival of the monsoon' (Interview with Shankarappa, 2I April 2018). Farmers pray in the hope that the rain god blesses them with a plentiful mangaru male (southwest monsoon) rainfall to bring the dry fields back to life; sweet dishes are offered to the rain god as prasad and then shared among temple attendees. But appeals to the rain god can also occur in a more spontaneous and less ritualized manner. 'Sometimes while working we sing to the god so that he grants us rain,' Shivamma explains. 'One of us women would say to the others, look it's not raining, let's sing.' If rains then arrive, they feel boundless joy and their beliefs are strengthened, she adds.

For these farming communities, such historically derived folk religious beliefs and rituals remain the crucial source of values, ethical norms, and emotional resilience, expressing their particular ontological way of being. On the one hand, beliefs help with the challenges encountered in everyday life, such as family losses, crop failures, or extreme weather disasters. On the other, the celebratory and collective dimensions of farming rituals, which cannot take place without women, provide positive motivation and social capacity to engage in sustainable foodways and agricultural practices. 'Without these occasions of joy and celebration, there would be great sadness in our villages,' Devaramma affirms.

\section{'Our weather has changed, the rains are so unpredictable now'}

Alongside positive memories and celebratory occasions, we also heard stories of hardship, of difficult experiences in both the past and present, 
particularly in relation to 'bargala', or droughts, which constantly threaten to disrupt or break down customary foodways, while posing a serious challenge to the rain god. Now in her eighties, Ramakka recalls a drought that occurred about 50 years ago, when she was a young woman with little children in the village of Billedalle. 'It lasted for over a year, all the crops had failed, there were no fair price shops back then and we couldn't afford to buy food from the local store, so we had to forage for bamboo rice and vegetables in the forest to feed the children. It was the greatest challenge I've faced in my life,' she observes (Interview with Ramakka, 6 March 20I8).

Ramanagara is part of the wider region of Mysore which in the past has been the epicentre of some of the worst droughts in southern India, including the calamitous drought-famine event of $1876-8$ when the failure of the southwest monsoon coupled with the colonial administration's reluctance to undertake either famine prevention or timely relief measures led to the deaths of a quarter of the population (Davis 200I, 46). While there has not been a recurrence of fatalities on this scale since, the Gazetteer of India reports an increasing incidence of severe droughts in the region from the latter part of the twentieth century (GOK I989, 230). During the drought of 2015-16, it was reported that only 147 out of the I,38I reservoirs in Ramanagara had any water left in them (Shiva Kumar 2016).

Although they do not use the term 'climate change', the most elderly of the farmers believe that the weather has become hotter, dryer, and less predictable over the course of their lifetimes in Kanakapura taluka. Lakshmi Bai recalls that when she was growing up in the I950s, 'it used to rain well, we could trust the weather: in those days summer lasted a full three months, it was usually mild with temperatures not exceeding 20-24 degrees, but these days they can reach 30-40 degrees, which is unbearable' (Interview with Lakshmi Bai, I2 March 2018). Shivamma concurs, observing that when she was a child, 'the weather was cooler, and I remember the hills and mountains being lush. Trees were not cut down, so the weather was good' (Interview with Shivamma, 27 April 2018). Prema from Kokreshalli village also remembers that when she was young, about 40 years ago, the lakes, wells, and canals were full of water. But, particularly since the turn of the century, the rains have been failing and they now have to draw water from bore wells. This has led to other problems as she explains: 'Farming land is always at its best with plenty of natural rainfall for nurturing our crops; with water from bore wells we don't quite get the same quality of yield. In those days we didn't use chemical fertilizers or pesticides against insects as with the 
good rains, there was plenty of greenery and weeds for the insects to feed on. But as the soil has become drier, they go for whatever crops we've planted' (Interview with Prema, 23 March 2018). Moreover, not only is there now less rain from the southwest monsoon during the main sowing season, but the rainfall itself has become more isolated, often occurring in one village but not in another, even one close by. The farmers suggest that one reason for the erratic rains is the considerable deforestation that has occurred in the region over the past $5^{0}$ years. Perhaps the loss of a sense of trust in weather patterns defines one of the crucial ways in which these farming communities experience, via personal memories, climate change on the ground. It is through their weather memories, and the experienced contrast between past and present, that Kanakapura farmers have built up a sense of the unpredictability and change in their local climate, enabling them to identify weather-related changes to familiar landscapes.

'Fifty years ago,' Ramakka observes, gazing towards the distant horizon from her farm in Billedale village, 'this region was virtually all forest. There was just one road, the one you can see from here, which was much narrower back then, where bullock-carts used to be the only traffic' (Interview with Ramakka, 6 March 2018). The past half-century has witnessed over 70 per cent loss of trees, vegetation, and water bodies in the districts of Bangalore and Bangalore Rural immediately to the east of Ramanagara. At the same time, in Ramanagara district itself, the once thick forests are reported to have 'almost vanished', with the forests in its four talukas substantially cut down and lands distributed to farmers by the government. Even the surviving forests have had their density reduced by 50 per cent through tree felling (GoI 20I4, 3-4): this is likely to have occurred as a result of the demand for firewood from farming households and from the rapidly growing urban centres of Karnataka. Climatologists have pointed out that deforestation on such a scale reduces the land's capacity to absorb the greenhouse gases resulting from human activities, thus contributing to a rise in land temperatures (IPCC 2019; Levin and Parsons 2019), as farmers seem to have experienced in Ramanagara. Thick tropical forests are also conducive to abundant rainfall as trees draw water from the ground through their roots and then release water vapour through their foliage into the atmosphere, which results in cloud formation (Pearce 2018). Significantly, patterns of declining rainfall over southern India during the southwest monsoon have been found to match regional forest cover loss (Paul et al. 2018), and Ramanagara would seem to provide a local illustration of this process. 
Deforestation and the consequent warming up of the local weather has also affected the habitat of forest animals, and many of the farmers expressed deep anxieties about the increasing forays and attacks on their crops by elephants, monkeys, and wild boars coming from the nearby forests in search of food and water. Shivamma accepts that the farmers' rural habitat has to be shared with wild animals, particularly as they live so close to the forests. She points out that animal intrusions on the family farm in Allanatha village have been happening as far back as she can remember, but such encroachments have now reached a scale where they impact on decisions regarding crop cultivation. In fact, she has stopped growing rice altogether following constant attacks by elephants and wild boars at harvest time. In January 2018, foraging elephants destroyed her entire ragi crop, a loss which warranted a claim for compensation from the Forest Department (Interview with Shivamma, 26 March 2018). Many of the farmers we spoke to declared that monkeys constitute another menace to ragi plants and that birds coming from the forest area cause havoc to small millet crops at an early stage of their growth. They suggest that this might be another reason for the decline in the cultivation of the small millets in Kanakapura. Prior to the annual harvest, Shivamma's family offer prasad to the monkey-god Hanuman. A sweet dish, banana jaggery, is prepared and fed to the monkeys on the farm. This ritual once again combines the spiritual with the secularwhile feeding the monkeys is part of a belief system designed to gain the god's favour and blessings for a plentiful crop, in this context it also has a practical purpose: to dissuade the animals from preying on ragi and vegetable crops such as aubergine and tomatoes when they are reaching maturity (Interview with Shivamma, 26 March 2018).

Although these farmers closely follow official weather forecasts, they continue to rely mainly on their knowledge of the various rains acquired from family elders and passed down through the generations, including forecasting abilities, to plan their crop operations during the agricultural season. Even back in the nineteenth century colonial revenue officials made careful note of the 27 different rains named after the lunar asterisms that guided the sequence of Karnataka farmers' tilling and sowing activities (Hazareesingh 2013, 93). The women tell us that farmers can predict the coming of rain when the coyla (the Asian cuckoo) starts singing or when the frogs make loud noises at night, and also when anthills begin to appear or when they see ants carrying grass and ragi seeds as food to their dens. 'It is when they notice this pattern of behaviour among ants that farmers themselves often start sowing their seeds,' Ramakka declares. She remembers that during a severe 
drought 'some time ago', which lasted over two years, there were no ragi seeds left to sow, so the farmers dug up the anthills and were able to find and sow some seeds. 'It is the ants who shared and gave us their seeds and preserved us from hunger and hardship,' she recalls (Interview with Ramakka, 6 March 2018).

The impact of the changing weather on the agricultural season is now a major concern. The combination of higher temperatures and decreased rainfall has resulted in a loss of soil moisture and a reduction in the period of crop growth. Shivamma feels that two of the early pre-monsoon rains known as revati male and ashwini male, which usually occur in March and early April and upon which the sowing of her sesame crop traditionally depended, are no longer as reliable as they were 20 years ago. 'We don't hear frogs making noise signalling their imminent arrival as much as in the past,' she observes. 'So we now pay particular attention to the rainfall expected in late April and May, the showers we call bharani male,' Lakshmi Bai adds. 'If these showers arrive, we can still feel confident about the rainfall for the main sowing season.' They continue to pray to the rain god and to consult astrologers about rain prospects for future seasons, but last year they had no answer, she admitted (Interview with Lakshmi Bai, 6 March 2018). She goes on to suggest that droughts are perhaps divine punishment because 'people have abandoned the wholesome practices of the past' (Interview with Lakshmi Bai, I2 March 2018). Regarding the April/May rains, she has noticed that in recent years the soil does not remain moist for long after these rains; however, this problem has been partly mitigated by the tractor which they began using about ${ }_{5} 5$ years ago. While most small farmers continue to use the wooden plough alongside the tractor, the new machine, Shivamma explains, 'has allowed us to work most of the land in a day. Before, when we were just using the plough, we tended, like in our grandmothers' time, to wait for the rains to fall in chronological order, but now with the tractor we can plough the land and start sowing after any of the rains.' This increase in resource endowment has helped her to adopt a climate adaptive strategy in relation to her main crop, ragi, and she now grows the three-month rather than the five-month variety that was predominantly cultivated 20 years ago, as the rainfall tends to be more reliable over the shorter period. 'The adri male rains (in June) give us the auspicious signal for the sowing of ragi and groundnut (another nitrogen-fixing crop) in a mixed cropping pattern,' she says, 'which increases their chances of survival' (Interview with Shivamma, 5 April 2018). Securing the annual ragi crop remains important for most smallholders, as minimizing risk 
and resilience in the face of the threat of rainfall failure continues to take the customary form of stocking up with a sufficient supply of millets for both food and fodder for two or three years. Kalamma and her family maintain a long-standing tradition of holding a permanent reserve supply of I8 sacks of ragi, which is deemed sufficient for about two years. Similarly, Prema stocks finger millet produced from nati (local) varieties for household consumption and which is never for sale. Concerns around climate-provoked food security ensure that finger millets remain a significant aspect of smallholding families' foodways in southern Karnataka, even if they are less dominant than they once were.

\section{'Everything in agriculture begins and ends with the seed'}

One male farmer recognized that 'while it is still we men who mainly decide on what crops to grow, it is the women who provide the seeds, the nurturing, and the know-how to make a success of the crops. From a very young age, girls are taught by mothers and grandmothers how to sow and preserve seeds. So they become experts in weeding and in selecting the seeds to be preserved' (Interview with Shankarappa, 2I April 2018). Ramakka adds that 'women have the fine touch required for handling, cleaning, and preparing the seeds. Men simply wouldn't have the patience' (Interview with Ramakka, 4 April 2018). Historically, in India, and the global South more generally, selecting, saving, storing, and reproducing local indigenous seeds have primarily been based on women's knowledge and expertise. In the early nineteenth century, colonial revenue officers in the Hubli-Dharwad region were already aware that annual seed-saving practices enabled local farmers to grow, for instance, I8 different varieties of sorghum (jowar or jola), the staple food of north Karnataka (Hazareesingh 2012, 9). In the world of the women smallholders, nati seeds possess agency as entities with life-producing capacities. Seed saving preserves these 'heirloom' or heritage varieties and helps communities maintain their local food culture and security, while exchanges with other farmers in the village community promote reciprocal and democratic relationships as they tend to cut across caste hierarchies (Pionetti 2005, I46, I56). 'When we exchange, only the quality of the seeds matters not the caste of the farmer,' Devaramma affirms (Interview with Devaramma, I2 March 2018). The seed preservation skills that are passed down through the generations constitute a substantial core of traditional 
farming knowledge (Sachs 1997; Nazarea 1998; Pionetti 2005, 2006; Ramprasad 2015).

However, acquiring such knowledge is not quite a seamless process of historical transmission. Inter-generational learning can be threatened, even ruptured, at any time by the lure of epistemologies associated with new crop technologies promoted by powerful interests such as state agencies, corporations, and external experts (Vicziany and Plahe 20i6). Green Revolution modernizers promised farmers that exchanging their indigenous seeds for industrially produced varieties would secure them higher yields, profits, and incomes, but this process also involved screening out the knowledge associated with local seeds and agroecological variety (Saha and Schmalzer 20I6). It also authorized the devaluing of cultural practices such as the oral transmission of experience and know-how, and of foodways based on the growing, preparing, and cooking of micronutrient-rich traditional foods such as millets and pulses. The Green Revolution model of food security implied an erasure of memory and history. In so doing, it also worked to further undermine women's status in the farming household as their knowledge of seeds and plants came to be seen as less relevant. Some of the elderly women confessed that their attempts to offer farming advice to their grandchildren were often met with comments like 'why don't you just sit quietly, this is our time, we don't need to listen to you'.

Most of the farmers we spoke to admitted that in the past they had either grown or were still growing hybrid varieties of ragi and other crops, using chemical fertilizers and pesticides. They recalled that such varieties of ragi, paddy, and pigeon pea were introduced in the region by the government around the turn of the century and that previously farmers used to cultivate only nati varieties based on indigenous seeds that had been saved and exchanged. Their experience of these hybrids was that, while yields did increase in good seasons, this was not often reflected in their incomes due to the high costs of the seeds and fertilizers which had to be purchased on the market. Moreover, Shivamma points out, 'we found that the chemicals used had an impact on the fertility of the soil, these plants seemed weaker in coming up and required a very particular pattern of rainfall. They needed more water to withstand the increasingly hot conditions.' Prema concurs, adding that the high cultivation costs and reduced yield of the hybrid ragi varieties have led her family to switch to mulberry cultivation as this provides a more secure monthly income. Our conversations suggest that many farmers in Kanakapura are returning to indigenous varieties of crops such as ragi, groundnut, and pigeon pea, using natural, 
home-made manures like jeevamrutha (cow-based fertilizer) and reverting to seed saving and exchange practices. 'We leave the roots of our nati plants in the soil to obtain next year's seeds,' Shivamma continues. 'If the seed harvest is plentiful, we keep some for ourselves and distribute the rest to farmer friends' (Interview with Shivamma, 5 April 2018). These farmers have found that by going back to cultivating indigenous varieties and producing their own fertilizers, they have significantly reduced the costs of their farming inputs and, in some cases, avoided serious debt. Moreover, with hotter weather and the increased frequency of droughts, seed saving from local plants which have a high capacity to survive such conditions has also emerged as a crucial climate adaptation strategy.

In this context, some women farmers in southern Karnataka have acquired a public reputation as seed savers, thus countering the devaluation of women's knowledge that is characteristic of Green Revolution epistemologies. Hombalamma from Denkanadoddi village is a recognized beeja matha (mother of seeds), and she travels across southern India imparting her knowledge and expertise to other farmers. 'I have no education, but I have knowledge. Men don't have this knowledge and they can't multi-task,' she observes when we visit her. She perceives seeds as living, almost human, entities. 'They will not grow unless nurtured and loved like you would a child,' she affirms (Interview with Hombalamma, 23 April 2018). She goes on to explain how, for over 20 years now, she has been preparing and using castor seed derivatives to preserve a wide variety of seeds. To ward off insects from the seeds of ragi and various pulses, she mixes them with roasted castor seeds. Once again, the grinding stone is prominent: she and her sons use it to pound and crush the castor seeds, with no machinery involved. The raw produce is then boiled in a copper pot, turmeric and soapnut are added, and through this process an organic castor oil emerges, which, she goes on to say, can also be used to treat bodily aches and pains successfully (Interview with Hombalamma, 25 March 2018). This pure oil is used to coat seeds from indigenous plants, thus preserving heirloom varieties and her family's 'seed sovereignty'. Their complete autonomy from the seed market enables them to grow over 50 varieties of food crops at the optimal time on their land which they have transformed into an organic farm. These crops include several varieties of ragi, foxtail millet, avarekai and broad beans, bottle gourd, pumpkin, tomato, pigeon pea, and other pulses. These crops reach maturation at different times during the season, thus minimizing risk to food security and ensuring a varied and nutritious diet. 


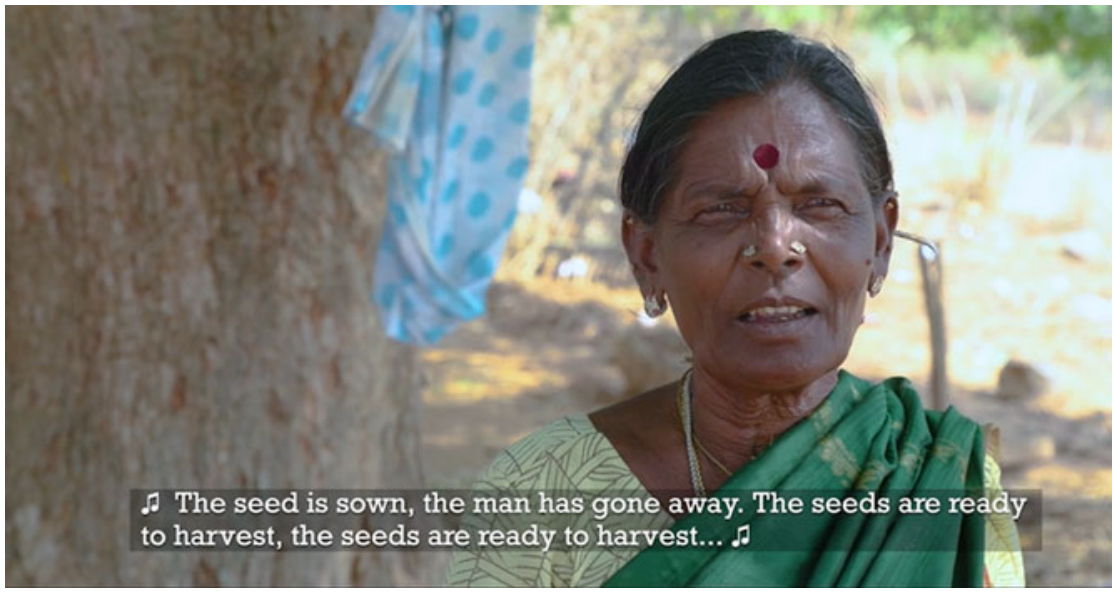

Figure 5. 'Beeja Matha (Mother of Seeds)'. Source: Sara Penrhyn Jones, Oral History project; https://vimeo.com/297665046.

This process of seed preservation underlines the ontological relationship between the natural and human worlds whereby seeds 'endlessly reproduce' both their own and human life through making food possible (Gutiérrez Escobar 20I6, I6). The nutritional variety of the seeds preserved by Hombalamma ensures that her family has at their disposal a wide range of nutritious dishes from the crops they grow: 'As I remember from the days of my grandfather, we have been eating tasty, nutritious food from locally raised crops on our farm,' she tells us. 'It makes no sense for our bodies to consume foods that we don't know from outside that don't give us strength.' Hombalamma and her three sons share the produce, keeping what is necessary to meet the requirements of their families and selling the rest. During our conversation she intimates that she would like us to hear one of her songs: she sings a harvest song, addressed to Mother Earth, which laments the men's absence from the field once they have sown the crops (see Figure 5). They spend many months away and are not even back in time for the harvesting season:

The seed is sown, the man has gone away

The seeds are ready to harvest, the crops are ready to harvest, But the man has not returned.

However, the women step in and harvest the crops and then save the seeds for the following year. On one level, the song is about women's resilience as custodians of the farming world, as opposed to the 'unreliability' of 
men. But it is also a social commentary about a more global phenomenon occurring not only in rural India but also in other parts of the global South: the issue of 'women left behind' as men migrate from villages to cities in search of additional income to support their families' livelihoods, resulting in the growing feminization of agriculture and a substantial increase in rural women's workloads.

The song lamenting the increasing out-migration of men from the rural world contrasts with Hombalamma's own hopeful narrative, which offers the nutrition-rich food security potentialities of women smallholders' nurturing and management of nati seeds and crops. However, development agencies and NGOs need to take seriously, recognize, and value the source of this knowledge which, as Hombalamma affirms, lies not in secular education but in an alternative epistemology which views humans, plants, seeds, and other non-human entities as interconnected and interdependent. Such a commitment from organizations seeking to promote social justice and equality would enable women's oral and experiential knowledges to acquire genuine public esteem and legitimacy in a society that remains attached to patriarchal norms. The prioritizing of women's knowledge and talents will be crucial to the successful reimagining of millet-centred foodways in southern India and beyond.

\section{Conclusion}

This article has presented an argument for the significance of oral history in accessing and shedding fresh light on the meanings of women smallholders' millet-based foodways. This method has revealed the rich range of historical and everyday cultural dimensions of women's experience with millets and the central place of ragi, in particular, in regionally specific ontologies of food and farming. In rural India, foodways open out beyond the secular and move into the orbit of folk religious beliefs and practices. The study has highlighted women farmers' cultural capabilities derived from inhabiting a world in which non-human entities such as deities, soils, seeds, animals, birds, and insects are intimately connected to humans and exercise significant influence over food and farming outcomes. This is a world that places particular emphasis on the transmission of beliefs and experiential knowledge through oral tradition. Women farmers' cultural capabilities are expressed in their fine-tuned sensibilities pertaining to the nurturing of seeds and crops, the preparation and taste of millet foods, and in the 
performing of songs and farming rituals that give meaning to the agricultural cycle. Women are central to the rituals and performances of food producing and food sharing which include offerings and acts of worship to deities. These practices express a fundamental belief in the necessity of auspicious endeavours that reach out to the divine at each important phase of the farming season. Here, spiritual, non-secular views and beliefs guide, celebrate, and sustain everyday farming and food cultures. It has been argued that these affirmative capabilities need to be recognized and placed at the heart of the social movement currently campaigning for a revival of millet-centred foodways in Karnataka and elsewhere in India, while also being given more space and importance in agrarian and development studies.

Oral history also enables the combining of history and culture in a single analytical framework, in the belief that only a partial and superficial understanding of cultural activity can be attained without historical investigation and knowledge. While an emerging, though still limited, literature is attempting to bring history and culture back into dialogue with development, it has tended to do so by focusing on one or the other, thereby maintaining them in separate realms. Seeking a more holistic approach, this article has suggested some of the strengths of oral history methodology, particularly the capacities to speak about and compare past and present, give voice to hidden and alternative narratives, recall cultural memories as a repository of knowledge and experience, and identify patterns of local social change. By enabling respondents to shape their narratives, our conversations enabled the women smallholders to actively reflect on their lives and experiences and to talk about matters they regarded as important. Narrating their autobiographical memories involved a cultural process of creating meanings and revealed how beliefs, ideas, and experiences originating in various pasts continue to influence women smallholders' contemporary practices and world views and, no doubt, imaginings of the future.

\section{References}

Abrams, Lynn. 20r6. Oral History Theory. London: Routledge.

Adapon, Joy. 2008. Culinary Art and Anthropology. Oxford: Berg Press.

Baillie Smith, Matt and Katy Jenkins. 2012. 'Editorial: Emotional Methodologies-The Emotional Spaces of International Development'. Emotion, Space, and Society 5, 2, pp. 75-77.

Bezner Kerr, Rachel. 20I4. 'Lost and Found Crops: Agrobiodiversity, Indigenous Knowledge, and a Feminist Political Ecology of Sorghum and Finger Millet in Northern Malawi'. Annals of the Association of American Geographers 104, 3, pp. 577-593. 
Bissonnette, Jean-François and Rodolphe De Koninck. 2017. 'The Return of the Plantation? Historical and Contemporary Trends in the Relation between Plantations and Smallholdings in Southeast Asia'. The Journal of Peasant Studies 44, 4, pp. 918-938.

Chera, Madeline. 2017. 'Transforming Millets: Strategies and Struggles in Changing Taste in Madurai'. Food, Culture and Society 20, 2, pp. 303-324.

Clammer, John. 2015. Art, Culture, and International Development. London: Routledge.

- 2018. 'Cultural Rights, Sustainability and Development: Are they Related? If so, How?'.

The Fournal of Law, Social Fustice and Global Development 22, pp. I-I2.

Davis, Mike. 2001. Late Victorian Holocausts. London: Verso.

Edelman, Marc and Wendy Wolford. 2017. 'Introduction: Critical Agrarian Studies in Theory and Practice'. Antipode 49, 4, pp. 959-976.

ETC Group. 2017. Who will Feed us? The Industrial Food Chain vs the Peasant Food Web. ETC Group Report, 3rd edn.

Frowde, Henry. 1908. The Imperial Gazetteer of India, Vol. XVIII. Oxford: Clarendon Press.

Government of India. 20I4. Census of India 20II. Karnataka. District Census Handbook Ramanagara. Bengaluru: Government Press.

Government of Karnataka. 1989. Gazetteer of India. Karnataka State, Bangalore Rural District. Bangalore: Government Press.

— 2018. Organics and Millets International Trade Fair. Bengaluru: Government Press.

Gutiérrez Escobar, Laura Maria. 20r6. 'The Political Ontology of Seeds: Seed Sovereignty Struggles in an Indigenous Resguardo in Colombia'. PhD thesis, University of North Carolina at Chapel Hill.

Hazareesingh, Sandip. 2012. 'Cotton, Climate and Colonialism in Dharwar, Western India, I840-1880'. Fournal of Historical Geography 38, pp. I-17.

2013. 'Territories of Conquest, Landscapes of Resistance: The Political Ecology of Peasant Cultivation in Dharwar, Western India, 1818-1840'. Joumal of Historical Geography 42, pp. 88-99.

Intergovernmental Panel on Climate Change (IPCC). 2019. Climate Change and Land. A Special Report on Climate Change, Desertification, Land Degradation, Sustainable Land Management, Food Security, and Greenhouse Gas Fluxes in Terrestrial Ecosystems. Geneva: IPCC Secretariat.

Jordan, Jennifer A. 2015. Edible Memory. The Lure of Heirloom Tomatoes and Other Forgotten Foods. Chicago: The University of Chicago Press.

Kantor, Hayden S. 2019. 'A Body Set between Hot and Cold: Everyday Sensory Labor and Attunement in an Indian Village'. Food, Culture and Society 22, 2, pp. 237-252.

Kaplan, David M. (ed.). 2012. The Philosophy of Food. Berkeley and Los Angeles: University of California Press.

Kong, Lily and Vineeta Sinha. 2015. 'Theorising Contemporary Foodscapes: Conceptual and Empirical Insights from Singapore'. In Kong, Lily and Vineeta Sinha (eds), Food, Foodways and Foodscapes: Culture, Community and Consumption in Post-Colonial Singapore. Singapore: World Scientific Publishing Company.

Landy, Frédéric. 2017. 'Rescaling the Public Distribution System in India: Mapping the Uneven Transition from Spatialization to Territorialisation'. Environment and Planning C: Politics and Space 35, I, pp. II3-129.

Levin, Kelly and Sarah Parsons. 2019. ' 7 Things to Know about the IPCG'S Special Report on Climate Change and Land'. World Resources Institute blog, published online on 8 August 2019, available at https://www.wri.org/blog/2019/o8/7-things-know-about-ipcc-specialreport-land-and-climate, [accessed I2 February 2020]. 
Liu, Pingyang, Juan M. Moreno, P. Song, E. Hoover and M. K. Harder. 2016. 'The Use of Oral Histories to Identify Criteria for Future Scenarios of Sustainable Farming in the South Yangtze River, China'. Sustainability 8, 859, pp. I-24.

Maass Wolfenson, Karla D. 2013. Coping with the Food and Agriculture Challenge: Smallholders' Agenda. Rome: Food and Agriculture Organization of the United Nations.

Moore, Henrietta L. 2018. 'Prosperity in Crisis and the Longue Durée in Africa'. The Journal of Peasant Studies 45, 7, pp. I50I-I5I7.

Morrison, Kathleen D. 20r6. 'From Millet to Rice (and Back Again?): Cuisine, Cultivation, and Health in Southern India'. In Schug, Gwen Robbins and Subhash R. Walimbe (eds), A Companion to South Asia in the Past. New York: Wiley Blackwell, pp. 358-374.

Nazarea, Virginia D. 1998. Cultural Memory and Biodiversity. Tucson: The University of Arizona Press.

Nussbaum, Martha. 2003. 'Capabilities as Fundamental Entitlements: Sen and Social Justice'. Feminist Economics 9, 2-3, pp. 33-59.

Osterhoudt, Sarah R. 2017. Vanilla Landscapes. Meaning, Memory, and the Cultivation of Place in Madagascar. New York: New York Botanical Garden Press.

Oxfam India. 2013. 'When Women Farm India's Land: How to Increase Ownership?', Oxfam India Policy Brief no. 8, October.

2017. 'An Economy that Works for Women'. Oxfam India Annual Report 2016-17.

Pande, Saket and Hubert H. G. Savenije. 2016. 'A Sociohydrological Model for Smallholder Farmers in Maharashtra, India'. Water Resources Research 52, 3, pp. 1923-1947.

Pandian, Anand. 2009. Crooked Stalks. Cultivating Virtue in South India. Durham: Duke University Press.

Paul, Supantha, Subimal Ghosh, K. Rajendran and Raghu Murtugudde. 20r8. 'Moisture Supply from the Western Ghats Forests to Water Deficit East Coast of India'. Geophysical Research Letters 45, 9, I6 May.

Pearce, Fred. 2018. 'Rivers in the Sky: How Deforestation is affecting Global Water Cycles'. Yale Environment 36o, published online on 24 July 2018 at https://e36o.yale.edu/features/howdeforestation-affecting-global-water-cycles-climate-change, [accessed II September 2019].

Pingali, Prabhu, Bhaskar Mittra and Andaleeb Rahman. 2017. 'The Bumpy Road from Food to Nutrition Security - Slow Evolution of India's Food Policy'. Global Food Security 15, pp. 77-84.

Pionetti, Carine. 2005. Sowing Autonomy. Gender and Seed Politics in Semi-Arid India. London: International Institute for Environment and Development.

— 2006. 'Seed Diversity in the Drylands: Women and Farming in South India'. Gatekeeper Series I26. London: International Institute for Environment and Development.

Raheja, Gloria Goodwin and Ann Grodzins Gold. 1994. Listen to the Heron's Words. Reimagining Gender and Kinship in North India. Berkeley: University of California Press (e-book).

Raju, S., Priya Rampal, R. V. Bhavani and S. C Rajshekar. 2019. 'Introduction of Millets into the Public Distribution System: Lessons from Karnataka', published online on 2 February 2019, available at http://ras.org.in/print/introduction_of_millets_into_the_public_distribution_ system, [accessed 22 February 2019].

Ramaswamy, Vijaya. 1993. 'Women and Farm Work in Tamil Folk Songs'. Social Scientist 2I, 9/II, Sept-Oct, pp. II $3^{-129 .}$

Ramprasad, Vanaja. 2015. Living on the Edge. Women, Agrobiodiversity, and Livelihood. Bangalore: Suhaas Graphics.

Ricciardi, Vincent, Navin Ramankutty, Z. Mehrabi, L. Jarvis and B. Chookolingo. 2018. 'How Much of the World's Food do Smallholders Produce?'. Global Food Security 17, pp. 64-72.

Sachs, Carolyn E. (ed.). I997. Women Working in the Environment. Washington: Taylor and Francis. 
Sachs, Carolyn E., Kishor Gajurel and Mariela Bianco. I997. 'Gender, Seeds, and Biodiversity'. In Sachs, Carolyn E. (ed.), Women Working in the Environment. Washington: Taylor and Francis, pp. $177^{-190 .}$

Saha, Madhumita and Sigrid Schmalzer. 20I6. 'Green-Revolution Epistemologies in India and China: Technocracy and Revolution in the Production of Scientific Knowledge and Peasant Identity'. The British fournal for the History of Science, Themes I, pp. I45-167.

Schiavoni, Christina M. 2017. 'The Contested Terrain of Food Sovereignty Construction: Toward a Historical, Relational and Interactive Approach'. The Journal of Peasant Studies 44, I, pp. I- 32 .

Sen, Amartya. 1999. Development as Freedom. Oxford: Oxford University Press.

Shah, Esha. 2012. 'Seeing like a Subaltern-Historical Ethnography of Pre-Modern and Modern Tank Irrigation Technology in Karnataka, India'. Water Alternatives 5, 2, pp. 507-538.

Shiva Kumar, M. T. 'I, 234 lakes in Ramanagaram, 159 in Mandya run dry', The Hindu, published online on I6 April 2016, available at thehindu.com/news/national/Karnataka/ I234-lakes-in-ramanagaram-I59-in-mandya-run-dry/article8531007.ece, [accessed I5 June 2019].

Siddhartha, A. 'Ragi over Rice', infochange, published online on 20 August 2012, available at infochangeindia.org/food-security/2I-agriculture/features/926I-ragi-over-rice, [accessed 20 July 2019].

Siegel, Benjamin Robert. 2018. Hungry Nation. Food, Famine, and the Making of Modern India. Cambridge: Cambridge University Press.

Spackman, Christy and Jacob Lahne. 2019. 'Sensory Labor: Considering the Work of Taste in the Food System'. Food, Culture and Society 22, 2, pp. I42-I5I.

Srinivas, M. N. 2012 [1976]. The Remembered Village. Delhi: Oxford University Press.

Vicziany, Marika and Jagjit Plahe. 2016. 'Food Security and Traditional Knowledge in India: The Issues'. South Asia: Fournal of South Asian Studies 40, 3, pp. 566-58г.

Wang, Qi, Qingfan Song and Jessie Bee Kim Koh. 2017. 'Culture, Memory, and Narrative Self-Making'. Imagination, Cognition, and Personality: Consciousness in Theory, Research, and Clinical Practice 37, 2, pp. 199-223.

Whitaker, James Andrew. 2019. 'Climatic and Ontological Change in the Anthropocene among the Makushi in Guyana'. Ethnos, published online 4 June 2019.

Wilson, Erin K. 2017. "Power Differences" and "the Power of Difference": The Dominance of Secularism as Ontological Injustice'. Globalizations I4, 7, pp. I076-го93.

Zeitlyn, David. 2015. 'Looking Forward, Looking Back'. History and Anthropology 26, 4, pp. $38 \mathrm{I}-407$. 